\title{
Association Between Insulin Resistance, Glucose Intolerance, and Hypertension in Pregnancy
}

\author{
Carlos Antonio Negrato, M.D., Ph.D., ${ }^{1}$ Lois Jovanovic, M.D., Ph.D., ${ }^{2}$ \\ Marcos Antonio Tambascia, M.D., Ph.D., ${ }^{3}$ Bruno Geloneze, M.D., Ph.D., ${ }^{3}$ Adriano Dias, Ph.D., ${ }^{4}$ \\ Iracema de Mattos Paranhos Calderon, Ph.D., ${ }^{5}$ and Marilza Vieira Cunha Rudge, Ph.D. ${ }^{5}$
}

\begin{abstract}
There is an association between insulin resistance, glucose intolerance, and essential hypertension, but the relation between insulin resistance, glucose intolerance, and hypertension diagnosed during pregnancy is not well understood. Transient hypertension of pregnancy, the new-onset nonproteinuric hypertension of late pregnancy, is associated with a high risk of later essential hypertension and glucose intolerance; thus, these conditions may have a similar pathophysiology. To assess the association between insulin resistance, glucose intolerance, essential hypertension, and subsequent development of proteinuric and nonproteinuric hypertension in pregnancy in women without underlying essential hypertension, we performed a prospective study comparing glucose (fasting, 1 and 2 hours postglucose load), insulin, glycosylated hemoglobin (HbA1c), high-density lipoprotein cholesterol (HDL-C), and triglycerides levels on routine screening for gestational diabetes mellitus. Women who developed hypertension in pregnancy $(n=37)$ had higher glycemic levels (fasting, 1 and 2 hours postglucose load) on a 100-gram oral glucose loading test, although only the fasting values showed a statistical significance $(p<0.05)$, and a significantly higher frequency of abnormal glucose loading tests, two hours after glucose load $(\geq 140 \mathrm{mg} / \mathrm{dL})(p<0.05)$ than women who remained normotensive $(n=180)$. Glucose intolerance was common in women who developed both subtypes of hypertension, particularly preeclampsia. Women who developed hypertension had greater prepregnancy body mass index $(p<0.0001)$, higher frequency and intensity of acanthosis nigricans $(p<0.0001)$, and higher baseline systolic and diastolic blood pressures $(p$ $\leq 0.0001$ for both), although all subjects were normotensive at baseline by study design; they also presented lower levels of HDL-C $(p<0.05)$. However, after adjustment for these and other potential confounders, an abnormal glucose loading test remained a significant predictor of development of hypertension $(p<0.05)$ and, specifically, preeclampsia $(p<0.01)$. There was a trend toward higher insulin and homeostasis model assessment-insulin resistance (HOMA-IR) levels in women developing any type of hypertension. When comparing women that remained normotensive to term with those with transient hypertension and preeclampsia, the preeclamptic women were born with lower weight $(p<0.05)$ and shorter length $(p<0.005)$; at screening they were older $(p<0.005)$, showed higher frequency and intensity of acanthosis nigricans $(p<0.0001)$, had higher prepregnancy BMI $(p<0.0005)$, as well as higher baseline systolic and diastolic blood pressures $(p \leq 0.0001$ for both). They also showed higher HOMA-IR levels that did not show a statistical significance. When glucose tolerance status was taken in account, an association was found between increasing indexes of hypertension $(p<$ $0.05)$ and of HOMA-IR $(p<0.05)$ with the worsening of glucose tolerance. These results suggest that insulin resistance and relative glucose intolerance are associated with an increased risk of new-onset hypertension in pregnancy, particularly preeclampsia, and support the hypothesis that insulin resistance may play a role in the pathogenesis of this disorder.
\end{abstract}

\footnotetext{
${ }^{1}$ Research Support Center, Bauru's Diabetics Association, Bauru, São Paulo, Brazil.

${ }^{2}$ Sansum Diabetes Research Institute, Santa Barbara, California.

${ }^{3}$ Department of Endocrinology and Diabetes, University of Campinas-UNICAMP, Bauru, São Paolo, Brazil.

${ }^{4}$ Research Support Center, and ${ }^{5}$ Department of Gynecology and Obstetrics, Botucatu Medical School, São Paulo State UniversityUNESP, Botucatu, Brazil.
} 


\section{Introduction}

$\mathbf{H}$ YPERTENSION, A COMMON DISORDER complicating pregnancy $(6-9 \%)$, remains a leading cause of maternal mortality (around 15\%) in the United States ${ }^{1}$ and worldwide. ${ }^{2}$ Hypertension is associated with glucose intolerance and insulin resistance. ${ }^{3,4}$ Increased insulin resistance found in normotensive offspring of hypertensive parents ${ }^{5,6}$ suggests that insulin resistance may precede the development of essential hypertension and may also cause it. Possible mechanisms by which insulin resistance or hyperinsulinemia may predispose to hypertension include increased renal sodium reabsorption,7 activation of sympathetic nervous system activity, ${ }^{8}$ and stimulation of cell membrane cation transport. ${ }^{9}$

Several investigators have reported insulin as a regulator of blood pressure during pregnancy, and they associated plasma insulin levels with hypertension. ${ }^{10}$ The role of insulin resistance in the pathogenesis of hypertension arising for the first time in pregnancy is still not well understood. ${ }^{11}$ Pregnancy is a state of increased insulin resistance ${ }^{12,13}$; hypertension in pregnancy generally presents in the third trimester when insulin resistance that normally occurs in pregnancy is higher. ${ }^{14,15}$ Some conditions that are associated with insulin resistance, like obesity ${ }^{16}$ and gestational diabetes, ${ }^{17-19}$ may be risk factors for the occurrence of hypertension in pregnancy. A role for insulin resistance in cases of new-onset hypertension in pregnancy is also suggested by the association of transient hypertension, or new-onset nonproteinuric hypertension of late pregnancy, with a high incidence of later essential hypertension. ${ }^{20,21}$

This study was performed to assess whether insulin resistance and glucose intolerance are associated with an increased risk of hypertension in pregnancy among women without essential hypertension, but with several degrees of glucose tolerance at the time of routine screening for gestational diabetes mellitus. Some of these women subsequently developed hypertension and some remained normotensive to term.

\section{Methods}

\section{Subjects}

The study population consisted of 217 women with singleton pregnancies, assigned to participate when the screening for gestational diabetes was performed in the third trimester, between 24 and 28 weeks of gestation, if they presented no previous or current history of hypertension. Two tests were performed to detect any degree of glucose intolerance: a 100-gram oral glucose tolerance test (OGTT) and a glycemic profile. The cutoff values for the OGTT were those proposed by Carpenter and Coustan (fasting $\geq 95 \mathrm{mg} / \mathrm{dL} ; 1$ hour $\geq 180 \mathrm{mg} / \mathrm{dL} ; 2$ hours $\geq 155 \mathrm{mg} / \mathrm{dL} ; 3$ hours $\geq 140$ $\mathrm{mg} / \mathrm{dL})^{22}$ and for the glycemic profile those proposed by Gillmer (fasting $\geq 90 \mathrm{mg} / \mathrm{dL}$ and/or 1-2 hours postprandial $\geq 130 \mathrm{mg} / \mathrm{dL} .^{23}$ The glycemic profile was done within a week after the OGTT. Patients were taught how to measure their glycemic levels using a glucose reflectance meter in the fasting state at 8 a.m., then postprandially at 10 a.m., midday, and at 2, 4, and 6 p.m. If the results were borderline (10 $\mathrm{mg} / \mathrm{dL}$ higher or lower than the cutoff values), tests were repeated. After these procedures they were classified into four groups: (1) group IA, normal OGTT and glycemic pro- file (normoglycemic or control group; (2) group IB, normal OGTT and abnormal glycemic profile (mild hyperglycemic group); (3) group IIA, abnormal OGTT and normal glycemic profile (gestational diabetes group); (4) group IIB, abnormal OGTT and glycemic profile (overt gestational diabetes group).

Among the women enrolled in the study, 37 presented with new-onset hypertension in index pregnancy and 180 remained normotensive to term. New-onset hypertension in pregnancy was defined as a systolic blood pressure (SBP) of $140 \mathrm{mmHg}$ or greater or diastolic blood pressure (DBP) of $90 \mathrm{mmHg}$ or greater, constituting a rise in SBP of $30 \mathrm{mmHg}$ or greater or in diastolic blood pressure of $15 \mathrm{mmHg}$ or greater over first-trimester values measured on at least two occasions more than 6 hours apart and developing after 24 weeks of gestation in a previously normotensive woman. ${ }^{24}$ Eighteen of the hypertensive women had transient hypertension, defined as hypertension without significant proteinuria (24-hour urinary protein $<300 \mathrm{mg}$ ); 19 women had preeclampsia, defined as hypertension in association with 24-hour urinary protein of $300 \mathrm{mg}$ or greater. The normotensive control group included women who did not develop hypertension during pregnancy or in the immediate postpartum period.

To avoid inclusion of essential hypertensive women in the study, we excluded those women for which we were unable to document a normal blood pressure reading in the first trimester, or, if this was unavailable, in the 6 months preceding pregnancy or at a 6-week postpartum visit. Women were also excluded if they had any underlying medical illness, such as renal or liver disease, connective tissue disease, or diabetes antedating pregnancy, or were taking any medications that could affect glucose tolerance or blood pressure. This study was approved by the Institutional Review Board of the School of Medicine of Botucatu-São Paulo State University-UNESP, Brazil.

\section{Data collection}

Maternal characteristics, such as age, parity, ethnicity, weight and length at birth, and weight and body mass index (BMI) prepregnancy, were obtained. At screening, weight, height, blood pressure, waist and hip circumference, and hip circumference were measured. Obesity was defined as a prepregnancy $B M I \geq 30 \mathrm{~kg} / \mathrm{m}^{2}$.

Blood samples were collected at the time the OGTT was done to determine fasting one and 2-hour postglucose load levels of glycemia, glycosylated hemoglobin (HbA1c), high-density lipoprotein cholesterol (HDL-C), triglycerides, and insulin. Blood pressure was routinely measured in all patients.

All glucose determinations were conducted using glucose oxidase method (Glucose-analyzer II Beckman, Fullerton, CA). Home blood glucose monitoring was performed with an Accu-chek Advantage II Glucometer (Roche Diagnostics $\mathrm{GmbH}$, Mannheim, Germany). HDL-C and triglycerides were measured by enzymatic colorimetric assay (Vitros 250, Ortho-Clinical Diagnostics, Rochester, New York). HbA1c was determined by high-performance liquid chromatography (HPLC) (Dia-Stat analyzer, Bio-Rad Laboratories, Hercules, CA) and insulin using a specific radioimmunoassay kit (Linco Research, St. Charles, MO). Laboratory standards quality were measured routinely. 
The homeostasis model assessment (HOMA-IR)was calculated to determine the degree of insulin resistance and the secretory capacity of $\beta$ cells, according to following equations, proposed by Mattews et al. ${ }^{25}$ : HOMA-IR $=$ glycemia $(\mathrm{mMol} / \mathrm{L}) \times$ insulin $(\mathrm{U} / \mathrm{mL}) / 22.5$. Reference value $=1.66 \pm$ 0.79 ; men $=1.69 \pm 0.72$; women $=1.65 \pm 0.81$; insulin resistance $\geq 2.71 .^{26} \quad$ HOMA- $\beta=$ insulin $\quad(\mathrm{U} / \mathrm{mL}) /$ glycemia $(\mathrm{mMol} / \mathrm{L})-3.5$. Reference value $=200-250$.

\section{Statistical analysis}

Means, standard deviations, and percentages were presented. Continuous data were compared among three (normotensive, transitory hypertension, and preeclampsia) or four (IA, IB, IIA, and IIB) groups using the analysis of variance (one-way, ANOVA) with Tukey posttest comparisons. Posttest for linear trend between column mean and column number was also used in some analyses. When necessary, an unpaired Student $t$-test or corrected Student $t$-test-Welch was used to compare two groups (normotensive vs. hypertensive). Discrete data among three (normotensive, transitory hypertension, and preeclampsia) or four (IA, IB, IIA, and IIB) groups were analyzed using the chi-squared test. When necessary, the Fisher exact test was used to compare the two conditions (normotensive vs. hypertensive). To detect possible correlations between independent and dependent or between two dependent variables, linear regression was applied and considered significant when $r>0.7$. A $p$ value $<0.05$ was considered statistically significant.

\section{Results}

Women who developed hypertension in pregnancy showed a greater prepregnancy BMI (31.05 versus 26.22 ) and higher frequency and intensity of acanthosis nigricans (77.7\% versus $49.1 \%$ ) ( $p \leq 0.001$ for both) than those who remained normotensive; and although all groups had normal blood pressure at baseline as required by study entry criteria, women who developed hypertension had significantly higher baseline SBP (129.50 $\mathrm{mmHg}$ versus $115.10 \mathrm{mmHg}$ ) and DBP $(83.80 \mathrm{mmHg}$ versus $75.10 \mathrm{mmHg}$ ) than women remaining normotensive to term ( $p \leq 0.001$ for both). Their SBP (126.20 mmHg versus 109.80 $\mathrm{mmHg}$ ) and DBP (85.40 $\mathrm{mmHg}$ versus $72.40 \mathrm{mmHg}$ ) were also higher at 24-28 weeks of gestation when the screening was performed, than women remaining normotensive to term ( $p \leq$ 0.001 for both). They also showed higher fasting glucose (99.83 $\mathrm{mg} / \mathrm{dL}$ vs. $88.86 \mathrm{mg} / \mathrm{dL}$ ) and lower HDL-C levels (56.09 $\mathrm{mg} / \mathrm{dL}$ vs. $63.15 \mathrm{mg} / \mathrm{dL})(p<0.05$ for both). They also presented higher levels of glucose intolerance $(p<0.05)$; had lower birth weight, shorter birth length, were older, more frequently multiparas, had higher waist-to-hip ratio, higher levels of glycemia 1 and 2 hours postglucose load at OGTT, and higher levels of $\mathrm{HbA} 1 \mathrm{c}$ and triglycerides, although not statistically significant (Table 1).

Table 1. Demographic and Clinical Variables in Women Remaining Normotensive to Term and Women Developing Hypertension in Pregnancy

\begin{tabular}{|c|c|c|c|}
\hline & $\begin{array}{l}\text { Normotensive } \\
\quad(\mathrm{n}=180)\end{array}$ & $\begin{array}{l}\text { Hypertension in pregnancy } \\
\qquad(\mathrm{n}=37)\end{array}$ & $\mathrm{p}$ value \\
\hline Maternal birth weight (grams) & $3274.38( \pm 627.01)$ & $3005.38( \pm 816.17)$ & 0.057 \\
\hline Maternal birth length $(\mathrm{cm})$ & $48.19( \pm 2.77)$ & $47.00( \pm 3.67)$ & 0.058 \\
\hline Age (years) & $30.58( \pm 5.93)$ & $31.97( \pm 5.31)$ & 0.189 \\
\hline Height (meters) & $1.63( \pm 0.06)$ & $1.63( \pm 0.06)$ & 0.999 \\
\hline Race (\% Caucasian) & 66.1 & 75.7 & 0.267 \\
\hline First pregnancy (\%) & 31.1 & 27.0 & 0.279 \\
\hline $\begin{array}{l}\text { Gestational age at OGTT } \\
\text { (weeks) }\end{array}$ & $26.84( \pm 4.05)$ & $26.48( \pm 3.90)$ & 0.647 \\
\hline Pregravid BMI $\left(\mathrm{kg} / \mathrm{m}^{2}\right)$ & $26.22( \pm 6.66)$ & $31.05( \pm 6.92)^{\mathrm{a}}$ & $<0.0001^{\mathrm{a}}$ \\
\hline Weight gain $(\mathrm{kg})$ & $11.10( \pm 6.5)$ & $11.50( \pm 6.40)$ & 0.735 \\
\hline Pregravid waist/hip ratio & $0.82( \pm 0.08)$ & $0.84( \pm 0.09)$ & 0.482 \\
\hline Acanthosis (\%) & 49.1 & $77.7^{\mathrm{a}}$ & $<0.0001$ \\
\hline \multicolumn{4}{|l|}{$\mathrm{BP}$ at baseline $(\mathrm{mmHg})$} \\
\hline Systolic & $115.10( \pm 17.60)$ & $129.50( \pm 27.80)^{\mathrm{a}}$ & $<0.001^{\mathrm{a}}$ \\
\hline Diastolic & $75.10( \pm 10.80)$ & $83.80( \pm 13.20)^{\mathrm{a}}$ & $<0.001^{\mathrm{a}}$ \\
\hline \multicolumn{4}{|l|}{ BP at week 24 (mmHg) } \\
\hline Systolic & $109.80( \pm 11.30)$ & $126.20( \pm 14.20)^{\mathrm{a}}$ & $<0.0001^{\mathrm{a}}$ \\
\hline Diastolic & $72.40( \pm 8.40)$ & $85.40( \pm 11.70)^{\mathrm{a}}$ & $<0.0001^{\mathrm{a}}$ \\
\hline $\begin{array}{l}\text { Fasting glucose at OGTT } \\
(\mathrm{mg} / \mathrm{dL})\end{array}$ & $88.86( \pm 29.15)$ & $99.83( \pm 27.13)^{\mathrm{a}}$ & $0.021^{\mathrm{a}}$ \\
\hline $\begin{array}{l}1 \text { hour postload at OGTT } \\
(\mathrm{mg} / \mathrm{dL})\end{array}$ & $158.10( \pm 59.30)$ & $174.03( \pm 57.40)$ & 0.164 \\
\hline $\begin{array}{l}2 \text { hours postload at OGTT } \\
(\mathrm{mg} / \mathrm{dL})\end{array}$ & $137.81( \pm 54.16)$ & $148.03( \pm 61.96)$ & 0.342 \\
\hline HbA1c $(\%)$ & $5.40( \pm 1.14)$ & $5.74( \pm 1.24)$ & 0.167 \\
\hline HDL-C (mg/dL) & $63.15( \pm 17.26)$ & $56.09( \pm 16.51)^{\mathrm{a}}$ & $0.030^{\mathrm{a}}$ \\
\hline Triglycerides (mg/dL) & $199.58( \pm 89.81)$ & $228.85( \pm 99.55)$ & 0.092 \\
\hline
\end{tabular}

aStatistically significant.

Note: OGTT, Oral glucose tolerance test; BMI, body mass index; BP, blood pressure; HbA1c, glycosylated hemoglobin; HDL-C, highdensity lipoprotein cholesterol. 
Those who developed transient hypertension in pregnancy, compared with those remaining normotensive to term, showed a greater prepregnancy BMI (31.05 vs. 26.22), higher frequency and intensity of acanthosis nigricans $(77.7 \%$ vs. $49.1 \%)$ ( $P \leq 0.001$ for both), and higher baseline SBP (123.90 $\mathrm{mmHg}$ versus $115.10 \mathrm{mmHg})$ and DBP $(80.60 \mathrm{mmHg}$ versus $75.10 \mathrm{mmHg}$ ) ( $p \leq 0.001$ for both). Their blood pressure, both systolic and diastolic, was also higher at screening (122.80 $\mathrm{mmHg}$ vs. $109.80 \mathrm{mmHg})$ and $(85.00 \mathrm{mmHg}$ vs. $72.40 \mathrm{mmHg})$, respectively, than the normotensive group. They also showed higher fasting glucose $(94.59 \mathrm{mg} / \mathrm{dL}$ vs. $88.86 \mathrm{mg} / \mathrm{dL}$ ) and lower HDL-C levels (50.59 mg/dLvs. $63.15 \mathrm{mg} / \mathrm{dL})(p<0.05$ for both). They were younger, had shorter stature, were more frequently multiparas, had greater weight gain, higher waist-to-hip ratio, higher 1-hour and lower 2-hour levels of glucose postload, and higher levels of $\mathrm{HbA} 1 \mathrm{c}$ and triglycerides that were not statistically significant.

Patients that developed preeclampsia, when compared with those that remained normotensive, were born with a lower weight (2723.85 g vs. $3274.38 \mathrm{~g})(p<0.0 .05)$, shorter length $(45.38 \mathrm{~cm}$ vs. $48.19 \mathrm{~cm})(p<0.005)$, were older $(34.87$ years vs. 30.58 years) $(p<0.005)$, had greater prepregnancy BMI (31.43 vs. 26.22) and higher frequency and intensity of acanthosis nigricans (77.7\% vs. $49.1 \%$ ) ( $p<0.001$ for both), higher baseline SBP (134.70 $\mathrm{mmHg}$ vs. $115.10 \mathrm{mmHg})$ and DBP (86.80 mmHg versus $75.10 \mathrm{mmHg}$ ) ( $p \leq 0.001$ for both). Their blood pressure, both systolic and diastolic, was also higher at screening: SBP (129.50 mmHg vs. $109.80 \mathrm{mmHg})$ and DBP ( $85.80 \mathrm{mmHg}$ vs. $72.40 \mathrm{mmHg}$ ), respectively ( $p \leq$ 0.001 for both). They also showed higher fasting glucose levels $(105.06 \mathrm{mg} / \mathrm{dL}$ versus $88.86 \mathrm{mg} / \mathrm{dL})$ than the normotensive group ( $p-0.05$ for both). They were taller, had higher parity, greater weight gain, higher waist-to-hip ratio, higher levels of glycemia 1 hour and 2 hours postglucose load, and higher levels of $\mathrm{HbA1c}$ and triglycerides that also showed no statistical significance (Table 2).

Insulin levels measured at the time OGTT was performed tended to be higher among women who developed hypertension in pregnancy $(16.25 \mathrm{U} / \mathrm{mL})$ than among those who remained normotensive $(12.80 \mathrm{U} / \mathrm{mL})$, although without statistical significance; but HOMA-IR levels (3.55 vs. 2.40) showed statistical significance between the two groups $(p<$ $0.05)$ (Table 3). When the hypertensive groups were analyzed separately, the group with preeclampsia presented the highest insulin levels, followed by the transient hypertension and the normotensive groups $(16.80 \mathrm{U} / \mathrm{mL}$ vs. $15.70 \mathrm{U} / \mathrm{mL}$ vs. $12.80 \mathrm{U} / \mathrm{mL}$ ), respectively; also the highest levels of HOMA-

Table 2. Demographic and Clinical Variables in Women Remaining Normotensive to Term and Women Developing New-Onset Hypertension in Pregnancy (Transient Hypertension or Preeclampsia)

\begin{tabular}{|c|c|c|c|c|}
\hline & $\begin{array}{l}\text { Normotensive } \\
\quad(\mathrm{n}=180)\end{array}$ & $\begin{array}{c}\text { Transient } \\
\text { hypertension } \\
(\mathrm{n}=18)\end{array}$ & $\begin{array}{l}\text { Preeclampsia } \\
\quad(\mathrm{n}=19)\end{array}$ & $\mathrm{p}$ value \\
\hline $\begin{array}{l}\text { Maternal birth weight } \\
\text { (grams) }\end{array}$ & $3274.38( \pm 627.01)$ & $3286.92( \pm 846.20)$ & $2723.85( \pm 707.09)^{\mathrm{a}}$ & $0.015^{\mathrm{a}}$ \\
\hline $\begin{array}{l}\text { Maternal birth length } \\
(\mathrm{cm})\end{array}$ & $48.19( \pm 2.77)$ & $48.62( \pm 2.40)$ & $45.38( \pm 4.07)^{\mathrm{a}}$ & $0.003^{\mathrm{a}}$ \\
\hline Age (years) & $30.58( \pm 5.93)$ & $28.91( \pm 5.44)$ & $34.87( \pm 3.20)^{\mathrm{a}}$ & $0.003^{\mathrm{a}}$ \\
\hline Height (meters) & $1.63( \pm 0.06)$ & $1.61( \pm 0.06)$ & $1.64( \pm 0.06)$ & 0.185 \\
\hline Race (\% Caucasian) & 66.1 & 72.2 & 78.9 & 0.120 \\
\hline First pregnancy (\%) & 31.1 & 27.8 & 26.3 & 0.073 \\
\hline $\begin{array}{l}\text { Gestational age at } \\
\text { OGTT (weeks) }\end{array}$ & $26.84( \pm 4.05)$ & $26.44( \pm 3.83)$ & $26.53( \pm 4.08)$ & 0.899 \\
\hline Pregravid BMI $\left(\mathrm{kg} / \mathrm{m}^{2}\right)$ & $26.22( \pm 6.66)$ & $31.05( \pm 6.92)^{\mathrm{a}}$ & $31.43( \pm 6.66)^{\mathrm{a}}$ & $<0.001^{\mathrm{a}}$ \\
\hline Weight gain $(\mathrm{kg})$ & $11.10( \pm 6.5)$ & $11.70( \pm 7.90)$ & $11.40( \pm 6.38)$ & 0,466 \\
\hline Pregravid waist/hip ratio & $082( \pm 0.08)$ & $0.83( \pm 0.12)$ & $0.85( \pm 0.08)$ & 0.733 \\
\hline Acanthosis $(\%)$ & 49.1 & $77.7^{\mathrm{a}}$ & $77.7^{\mathrm{a}}$ & $<0.0001$ \\
\hline \multicolumn{5}{|l|}{$\mathrm{BP}$ at baseline $(\mathrm{mmHg})$} \\
\hline Systolic & $115.10( \pm 17.60)$ & $123.90( \pm 25.70)^{\mathrm{a}}$ & $134.70( \pm 29.30)^{\mathrm{a}}$ & $<0.001^{\mathrm{a}}$ \\
\hline Diastolic & $75.10( \pm 10.80)$ & $80.60( \pm 12.60)^{a}$ & $86.80( \pm 13.30)^{\mathrm{a}}$ & $<0.001^{\mathrm{a}}$ \\
\hline \multicolumn{5}{|l|}{$\mathrm{BP}$ at week $24(\mathrm{mmHg})$} \\
\hline Systolic & $109.80( \pm 11.30)$ & $122.80( \pm 13.60)^{\mathrm{a}}$ & $129.50( \pm 14.30)^{\mathrm{a}}$ & $<0.001^{\mathrm{a}}$ \\
\hline Diastolic & $72.40( \pm 8.40)$ & $85.00( \pm 11.50)^{\mathrm{a}}$ & $85.80( \pm 12.10)^{\mathrm{a}}$ & $<0.001^{\mathrm{a}}$ \\
\hline $\begin{array}{l}\text { Fasting glucose at } \\
\text { OGTT }(\mathrm{mg} / \mathrm{dL})\end{array}$ & $88.86( \pm 29.15)$ & $94.59( \pm 27.76)^{a}$ & $105.06( \pm 26.30)^{a}$ & $0.041^{\mathrm{a}}$ \\
\hline $\begin{array}{l}1 \text { hour postload at OGTT } \\
(\mathrm{mg} / \mathrm{dL})\end{array}$ & $158.10( \pm 59.30)$ & $162.10( \pm 50.20)$ & $185.90( \pm 63.10)$ & 0.199 \\
\hline $\begin{array}{l}2 \text { hours postload at } \\
\text { OGTT }(\mathrm{mg} / \mathrm{dL})\end{array}$ & $137.81( \pm 54.16)$ & $128.56( \pm 51.75)$ & $167.50( \pm 66.70)$ & 0.088 \\
\hline HbA1c $(\%)$ & $5.40( \pm 1.14)$ & $5.61( \pm 1.38)$ & $5.85( \pm 1.13)$ & 0.238 \\
\hline HDL-C (mg/dL) & $63.15( \pm 17.26)$ & $50.59( \pm 17.28)^{\mathrm{a}}$ & $60.98( \pm 14.56)$ & $0.020^{\mathrm{a}}$ \\
\hline Triglycerides (mg/dL) & $199.58( \pm 89.81)$ & $234.78( \pm 71.80)$ & $223.58( \pm 120.94)$ & 0.227 \\
\hline
\end{tabular}

aStatistically significant.

Note: OGTT, Oral glucose tolerance test; BMI, body mass index; BP, blood pressure; HbA1c, glycosylated hemoglobin; HDL-C, highdensity lipoprotein cholesterol. 
Table 3. Glucose Tolerance Status Variables in Women Remaining Normotensive to Term and Women Developing Hypertension in Pregnancy

\begin{tabular}{lccc}
\hline & Normotensive & Hypertension & $\mathrm{p}$ value \\
\hline Insulin $(\mathrm{U} / \mathrm{mL})$ & $12.80( \pm 10.90)$ & $16.25( \pm 9.75)$ & 0.309 \\
HOMA-IR & $2.40( \pm 1.80)$ & $3.55( \pm 1.95)^{\mathrm{a}}$ & $0.036^{\mathrm{a}}$ \\
Glucose tolerance status $(\%)$ & & & $0.044^{\mathrm{a}}$ \\
Group IA $(n=53)$ & 92.45 & 7.55 & \\
Group IB $(n=57)$ & 86.21 & 13.79 & \\
Group IIA $(n=20)$ & 78.00 & 22.00 & \\
Group IIB $(n=86)$ & 76.74 & 23.26 & \\
\hline
\end{tabular}

aStatistically significant.

Note: HOMA-IR, Homeostasis model assessment-insulin resistance.

IR were found in the preeclampsia group followed by the transient hypertension and the normotensive groups (3.90 vs. 3.20 vs. 2.40 ), respectively, without statistical significance (Table 4).

Taking in account two diagnostic methods, the 100-gram OGTT and the glycemic profile to determine glucose tolerance status, women that presented new-onset hypertension in pregnancy belonged significantly to the more glucose-intolerant groups when compared to the normotensive women (7.55\%, IA; $13.79 \%$, IB; $22.00 \%$, IIA; and $23.26 \%$, IIB; vs. $92.45 \%$, IA; $86.21 \%$, IB; $78.00 \%$, IIA; 76.74\%, IIB), respectively $(p<<0.05)$. The same trend was observed when patients were analyzed by subtypes of hypertension; transient hypertension was more frequently found in the group presenting mild gestational hyperglycemia (IB) and preeclampsia in the gestational diabetes (IIA) $(p<0.05)$ (Table 4$)$.

No absolute fasting glucose level distinguished reliably between women developing new-onset hypertension in pregnancy and normotensive women. Still, a significantly higher percentage of women who developed hypertension $(43.24 \%)$ than remained normotensive $(27.80 \%)$ had OGTT glucose levels of $140 \mathrm{mg} / \mathrm{dL}$ or greater, 2 hours after glucose load ( $p<0.05$ ); particularly women developing preeclampsia $(57.89 \%)$ had glucose levels in this range $(p<0.05)$

Using a muitivariate analysis to assess the risk for new-onset hypertension in pregnancy associated with an OGTT glucose level of $140 \mathrm{mg} / \mathrm{dL}$ or greater, 1 or 2 hours after glucose load, and after adjustment for maternal age, race (Caucasian versus non-Caucasian), and gestational age at OGTT, high glucose levels both in fasting, 1 hour and 2 hours postglucose load were associated with a significantly increased risk of hypertension $(p<0.05)$.

\section{Discussion}

Insulin resistance is associated with and may be causal in essential hypertension. ${ }^{4,5,7-9}$ The results of the present study indicate a strong association between glucose intolerance, insulin resistance, and subsequent development of hypertension in pregnancy, particularly the preeclampsia subtype. Glucose tolerance was evaluated before the development of hypertension, and it was found that relative glucose intolerance may precede the onset of this disorder. Women with insulin-dependent diabetes antedating pregnancy are known to have an increased risk of hypertension in pregnancy, ${ }^{27}$ but these women primarily have insulin deficiency rather than insulin resistance, and they often have renal dysfunction that might underlie blood pressure elevation. More recently, risk of hypertension in pregnancy has been reported by some, ${ }^{18,28-31}$ although not all ${ }^{32,33}$ investigators to be increased among women with gestational diabetes, a disorder associated with underlying insulin resistance. ${ }^{34}$ Some, ${ }^{31,35}$ but not other, ${ }^{18}$ studies have suggested a relation between less-striking degrees of glucose intolerance and subsequent hypertension in pregnancy.

The present study carefully excluded preexisting essential hypertension by documentation of normal blood pressures before, early in pregnancy, and after the pregnant state. Although not uncommon during the reproductive years, essential hypertension is often undiagnosed in this population;

Table 4. Glucose Tolerance Status Variables in Women Remaining Normotensive to Term and Women Developing New-Onset Hypertension in Pregnancy (Transient Hypertension or Preeclampsia)

\begin{tabular}{lccr}
\hline & Normotensive & $\begin{array}{c}\text { Transient } \\
\text { hypertension }\end{array}$ & Preeclampsia \\
\hline Insulin $(\mathrm{U} / \mathrm{mL})$ & $12.80( \pm 10.90)$ & $15.70( \pm 10.00)$ & $16.80( \pm 9.47)$ \\
HOMA-IR & $2.40( \pm 1.80)$ & $3.20( \pm 2.10)$ & $3.90( \pm 1.90)$ \\
Glucose tolerance status $(\%)$ & & & 0.077 \\
Group IA $(n=53)$ & 92.45 & 5.66 & 1.89 \\
Group IB $(n=57)$ & 86.21 & 10.28 & 3.51 \\
Group IIA $(n=20)$ & 78.00 & 5.00 & 17.00 \\
Group IIB $(n=86)$ & 76.74 & 9.30 & 13.96 \\
\hline
\end{tabular}

aStatistically significant.

Note: HOMA-IR, Homeostasis model assessment-insulin resistance. 
many women do not routinely see a physician before pregnancy, and they may not receive obstetric care until the second trimester of pregnancy, when there is a normal physiological decrease in blood pressure. Confirmation of previous or subsequent normotension among women diagnosed with hypertension in pregnancy in the present study eliminates the possibility that the glucose intolerance noted in these women could be explained by misclassification of women with preexisting essential hypertension. We also distinguished between subtypes of hypertension in pregnancy and observed a significantly higher frequency of glucose intolerance (abnormal OGTTs) among women who developed any type of hypertension. The increased incidence of later essential hypertension reported among women with transient hypertension and preeclampsia ${ }^{36}$ is consistent with this observation.

Significant associations were also found between new-onset hypertension in pregnancy and prepregnancy BMI and blood pressures earlier in pregnancy. These observations are consistent with previously reported associations between hypertension in pregnancy and obesity, 15,37 and excessive pregnancy weight gain ${ }^{16}$ and blood pressure in the second trimester or earlier. ${ }^{38}$ The greater BMIs noted among women who are subsequently diagnosed with preeclampsia may reflect early evidence of the edema characteristic of this disorder or, alternatively, could be pathogenic.

The observation of higher first-trimester blood pressures in initially normotensive women who subsequently develop transient hypertension suggests an underlying tendency to high blood pressure in these women that is unmasked or exaggerated by pregnancy. Underlying essential hypertension is considered a risk factor for development of preeclampsia $^{21,24}$; our observation of higher baseline blood pressures among women developing this disorder indicates that relative increases in blood pressure within the normal range are also associated with increased risk of developing the disease.

The relation between glucose tolerance and subsequent development of hypertension in pregnancy remained significant in our population after adjustment for maternal age, race, gestational age at OGTT, and prepregnancy BMI. The trend toward higher insulin levels in women who developed hypertension in pregnancy, although not statistically significant, nevertheless suggests a role for insulin resistance or hyperinsulinemia in the pathogenesis of this disorder. A link between insulin resistance and development of hypertension in pregnancy is also supported by the association of hypertension in pregnancy with increased BMI in this and other studies. ${ }^{15,21,24}$

The finding of an association between mild degrees of hyperglycemia (group IB) and higher incidence of transient hypertension suggest that even slightly higher levels of insulin are associated with an increased risk for developing these conditions. ${ }^{31}$ Some investigators consider primigravidity to be a criterion for the diagnosis of preeclampsia ${ }^{36}$; however, primigravidas $(27.03 \%)$ in our study were less frequently diagnosed with transient hypertension and preeclampsia than multigravidas $(72.97 \%)$.

In summary, our results indicate that glucose intolerance may be an important predictor of the development of new-onset hypertension in pregnancy. These data provide support for the hypothesis that insulin resistance may have a role in the pathogenesis of hypertension in pregnancy.

\section{Acknowledgments}

We thank Professor Alex Rafacho and Professor José Roberto Bosqueiro for helping in the statistical analyses and in computing data.

\section{References}

1. Diagnosis and management of preeclampsia and eclampsia. ACOG practice bulletin no.33: American College of Obstetricians and Gynecologists. Obstet Gynecol 2002;99:159-167.

2. Villar J, Say L, Shennan A, Lindheimer M, Duley L, CondeAgudelo A, Merialdi M. Methodological and techinical issues related to the diagnosis, screening, prevention and treatment of preeclampsia and eclampsia. Int J Gynaecol $\mathrm{Ob}$ stet 2004;85(Suppl.1):S28-S41.

3. Reaven GM. Banting lecture 1988: Role of insulin resistance in human disease. Diabetes 1988;37:1595-1607.

4. Ferrannini E, Buzzigoli G, Bonnadonna R, Giorico MA, Oleggini M, Graziadei L,Pedrinelli R, Brandi L. Bevilacqua S. Insulin resistance in essential hypertension. $\mathrm{N} \mathrm{Engl} \mathrm{J} \mathrm{Med}$ 1987;317:350-357.

5. Beatty OL, Harper R, Sheridan B, Atkinson AB. Insulin resistance in offspring of hypertensive parents. $\mathrm{Br} \mathrm{Med} \mathrm{I}$ 1993;307:92-96.

6. Dabelea D, Pettit D. Long-term implications: child and adult. In Hod M, Jovanovic L, Di Renzo GC,Leiva A, Langer O, eds. Textbook of Diabetes and Pregnancy. London: Martin Dunitz; 2003: 628 pp.

7. DeFronzo RA, Cooke C, Andres R, Faloona GR, Davis PJ. The effect of insulin in renal handling of sodium, calcium, potassium, and phosphate in man. I Clin Invest 1975;55: 845-855.

8. Rowe JW, Young JB, Minaker KL. Stevens AL, Pallotta J, Landsberg L. Effect of insulin and glucose infusions on sympathetic nervous system activity in normal man. Diabetes 1981;30:219-225.

9. Doria A, Fioretto P, Avogaro A. Carraro A, Morocutti A, Trevisan R, Frigato F, Crepaldi G, Viberti O, Nosadini R. Insulin resistance is associated with high sodium-lithium countertransport in essential hypertension. Aro J Physiol 1991;261:E684-E691.

10. Hamasaki T, Yasuhi I, Masuki H, Ishimaru T. Hyperinsulinemia increases the risk of gestational hypertension. Int I Gynecol Obstet 1996;55:141-145.

11. Bryson CL, Ioannou GN, Rulyak SJ, Critchlow C. Association between gestational diabetes and pregnancy-induced hypertension. Am J Epidemiol 2003;158:1148-1153.

12. Rodie VA, Freeman DJ, Sattar N, Greer IA. Pre-eclampsia and cardiovascular disease: metabolic syndrome of pregnancy? Atherosclerosis 2004;175:189-202.

13. Parretti E, Lapolla A, Dalfrà M, Pacini G, Mari A, Cioni R, Marzari C, Scarselli G, Mello G. Preeclampsia in lean normotensive normotolerant pregnant women can be predicted by simple insulin sensitivity indexes. Hypertension 2006;47 449-453.

14. Di Cianni G, Miccoli R, Volpe L, Lencioni C, Del Prato S. Intermediate metabolism in normal pregnancy and in gestational diabetes. Diabetes Metab Res Rev 2003;19:259-270.

15. Eskenazi B, Fenster L, Sidney S. A multivariate analysis of risk factors for pre-eclampsia. IAMA 1991;266:237-241.

16. Langer O, Yogev $Y$, Xenakis E M J, Brustman L. Overweight and obese in gestational diabetes: The impact of pregnancy outcome. Am J Obstet Gynecol 2005;192:1768-1776.

17. Buchanan TA, Xiang AH. Gestational diabetes mellitus. I Clin Invest 2005;115:485-491. 
18. Suhonen L, Teramo K. Hypertension and pre-eclampsia in women with gestational glucose intolerance. Acta Obstei Gynecol Scand 1993;72:269-272.

19. Moore T. Diabetes in pregnancy. In Maternal-fetal Medicine: Principles and Pratice, 5th ed. Creasy RK, Resnik R, Iams JD, eds. Philadelphia: Saunders; 2004: 1023-1061.

20. Pouta A, Hartikainen A, Sovio U, Gissler M, Laitinen J, McCarthy MI, Roukonen A, Elliot P, Järvelin M. Manifestations of metabolic syndrome after hypertensive pregnancy. $\underline{H y}$ pertension 2004;43:825-831.

21. Sattar N, Greer IA. Pregnancy complications and maternal cardiovascular risk:opportunities for intervention and screening? Br Med I 2002;325:157-160.

22. Carpenter MW, Coustan DR. Criteria for screening test for gestational diabetes. Am I Obstet Gynecol 1982;144:768-773.

23. Gillmer MDG, Beard RW, Brooke FM, Oakley NW. Carbohydrate metabolism in pregnancy. Br Med I 1975;3:399-404.

24. Solomon CG, Graves SW, Greene MF, Seely EW.Glucose intolerance as a predictor of hypertension in pregnancy. $\underline{\mathrm{Hy}-}$ pertension 1994;23:717-721.

25. Mathews DR, Hosker JP, Rudenski AS, Naylor BA, Treacher DF, Turner RC. Homeostasis model assessment: Insulin resistance and beta-cell function from fasting plasma glucose and insulin concentrations in man. Diabetologia 1985;28: 412-419.

26. Geloneze B, Repetto EM, Geloneze SR et al. The threshold value for insulin resistance HOMA-IR) in an admixtured population. IR in the Brazilian Metabolic Syndrome Study. Diab Res Clin Pract 2005;72:219-220.

27. Greene MF, Hare JW, Krache M, Philippe M, Barss VA, Saltzman DH, Nadel A, Younger MD, Schenl JE. Prematurity among insulin-requiring diabetic gravid women. Aro J Obstei Gynecol 1989;161:106-111.

28. Aberg A, Rydhstroem H, Frid A. Impaired glucose tolerance associated with adverse pregnant outcome: a population based study in southern sweden. Am I Obstet Gynecol 2001; 184:77-83.

29. Davey DA, I Mac Gyllivray. The classification and a definition of the hypertensive disorders of pregnancy. Am J Obstet Gynecol 1984;158:892.
30. Montoro MN, Kjos SL, Chandler M, Peters RK, Xiang AH, Buchanan TA. Insulin resistance and preeclampsia in gestational diabetes mellitus. Diabetes Care 2005;28:1995-2000.

31. Negrato C A, Jovanovic L, Tambascia MA, Calderon ID, Geloneze B, Dias A, Rudge MV. Mild gestational hyperglycaemia as risk factor for metabolic syndrome in pregnancy and adverse perinatal outcomes. Diabetes Metab Res Rev 2008;24(4):324-330.

32. Jacobson JD, Cousins L. A population-based study of maternal and perinatal outcome in patients with gestational diabetes. A,n J Obstei Gynecol 1989;161:981-986.

33. Magee MS, Walden CE, Benedetti TJ. Knopp RH. Influence of diagnostic criteria on the incidence of gestational diabetes and perinatal morbidity. IAMA 1993;269:609-615.

34. Ward WK, Johnston CLW, Beard JC. Benedetti TJ, Halter JB, Porte D. Insulin resistance and impaired insulin secretion in subjects with histories of gestationai diabetes mellitus. Diabetes 1985;34:861-869.

35. Bo Simona, Menato G, Gallo M-L et al: Mild gestational hyperglycemia, the metabolic syndrome and adverse neonatal outcomes. Acta Obstet Gynecol Scand 2004;83:335-340.

36. Fisher KA, Luger A, Spargo BH, Lindheimer MD. Hypertension in pregnancy: clinical pathological correlations and remote prognosis. Medicine. 1981;60:267-276.

37. Scheafer-Graf UM, Hever R, Kilavuz O, Pandura A, Henrich W, Vetter K. Maternal obesity not maternal glucose values correlates best with high rates of fetal macrosomia in pregnancies complicated by gestational diabetes. L Perinat Med. 2002;30:313-21.

38. Lucas MJ: Diabetes complicating pregnancy. Obstet Gynecol Clin North Am 2001;28:513-536.

Address reprint requests to: Carlos Antonio Negrato, M.D., Ph.D. Research Support Center Bauru's Diabetics Association Rua Saint Martin 27-07 Bauru, São Paulo, Brazil 17043-081

E-mail: carlosnegrato@uol.com.br 
This article has been cited by:

1. Giuseppe Maria Maruotti, Laura Sarno, Raffaele Napolitano, Laura Letizia Mazzarelli, Filomena Quaglia, Angela Capone, Alfredo Capuano, Pasquale Martinelli. 2012. Preeclampsia in women with chronic kidney disease. Journal of Maternal-Fetal and Neonatal Medicine 25:8, 1367-1369. [CrossRef]

2. Sushma Potti, Neetu J. Jain, Dimitrios S. Mastrogiannis, Vani Dandolu. 2012. Obstetric outcomes in pregnant women with diabetes versus hypertensive disorders versus both. Journal of Maternal-Fetal and Neonatal Medicine 25:4, 385-388. [CrossRef] 